\title{
无公害茶叶种植管理技术研究
}

\author{
林斌结 \\ 泰顺县雅阳镇农业公共服务中心 \\ DOI:10.32629/as.v2i4.1613
}

[摘 要] 随着人们对健康和科技的重视, 越来越多无公害产品进入人们的视野。其中无公害茶叶因其规范操作,质量达标, 有益 健康而受到重视。我们说的无公害茶叶是指在无公害生产环境条件下,按特定的生产操作规程生产,成品茶的农药残留、重金 属和有害微生物等污染物指标,卫生质量指标达到国家有关标准要求,对人体健康没有危害。基于此, 本文就无公害茶叶的种植 和管理提出几点建议。

[关键词] 无公害茶叶; 种植; 管理

无公害茶叶种植与普通茶叶种植都属于传统农艺, 其共 同点都是需要根据茶树自身的生物学特性, 为它们创造良好 的生长环境, 使茶树种植产量增加、质量更优。不同之处在 于, 无公害茶叶种植对茶园的选地、建设以及茶树的种植管 理具有更高的技术要求。绿色无公害茶叶的种植不仅能满足 其功能上的需要, 对茶文化的发展也起到了推动的作用, 对 此, 国家科研部门, 应加大对绿色无公害茶叶种植技术与管 理技术的研究, 从而保证茶叶种植的质量和效率。

\section{1 茶的功效概述}

在养生方面, 茶的利用价值、保健作用有很多。例如, 茶能降低心脑血管疾病的发病率, 而且具有降低胆固醇和血 压、抗压力和抗焦虑的作用, 能够提高人体免疫力, 还有减肥 的效果。现在越来越多的人喜欢喝茶, 无公害茶的关注度也 将会越来越高。有关资料显示, 茶对大脑细胞有保护作用, 当用脑过度的时候, 茶可以缓解大脑的疲劳; 老人适当喝茶 有利于能够改善人的记忆力和防止出现早老性痴呆。茶还可 以清除血管或者大肠中的堵塞物, 促进血液循环。

\section{2 无公害茶叶种植管理技术分析}

2.1绿色无公害茶园的建设

在绿色无公害茶叶种植中, 茶园的建设具有非常重要的 作用, 茶叶的质量受地理环境因素、自然环境因素以及地质条 件因素的影响较大, 因此, 在茶园选址方面要加大重视程度。

\subsection{1土壤的选择}

茶叶对土壤的要求较高, 其土壤的 $\mathrm{pH}$ 值要在 $4.0 \sim 6.0$, 尽量选择土壤较软的地区, 避免土壤对茶树的根部造成伤害 而影响生长, 另外, 其选择土壤的肥力要强, 保障茶树的正常 生长。

\subsection{2水源的选择}

要根据茶园的实际灌溉面积选择水源, 避免出现灌溉水 源不足等问题, 其水质要在灌溉前送到检测中心检测, 避免 水质对茶叶产生影响, 同时, 要合理使用灌溉方法, 节省水资 源的使用。
2.1.3地理环境的选择
海拔高度要小于 $1500 \mathrm{~m}$, 昼夜温差要小于 $10^{\circ} \mathrm{C}$, 另外, 降

水量及光照也是需要重点考虑的地方。茶园在建设中还需要 考虑一个问题, 要合理设置茶园道路的宽度, 要保证茶园管 理人员可以顺利通行, 避免在行走过程中对茶树造成损伤, 而影响茶树的正常生长。

\section{2 无公害茶园茶树的选种与种植 \\ 2.2.1选择良种}

因地制宜, 茶树品种尽量采用国家专业部门审定通过的 推广品种, 即选择优质的茶树品种, 所选品种要具有抗寒性、 抗旱性、抗病虫害、适应性强、制优率高的优势。为充分提 高茶叶的品质, 增加茶园的经济效益, 要将不同发芽期和特 性的品种按发芽期的早、中、晚一定比例进行搭配, 比较合 理的比例为特早、早生品种约占 $40 \%$ 左右, 中生、晚生品种约 各占 $30 \%$ 左右。从外地引进种苗时, 须经植检部门检疫认可后 方能种植, 以防止外地有而本地没有的病虫侵入本地。

\subsection{2茶树种植}

茶树区块大小一般以不超过 10 亩为宜, 茶行长度以不超 过 $50 \mathrm{~m}$ 为宜。合理密植, 每亩用苗量均为 5350 株左右。种植前 施足底肥, 以有机肥和矿物源肥料为主, 目前移栽茶苗多采 用开沟或开穴种植法, 种植时要把茶根系舒展开, 盖上细土, 用手或用脚将土压紧, 使茶苗根系和湿土接触良好。种植后 一定要淋足定根水, 然后在根部四周撒上一层细土, 有条件 的可以铺草保湿, 减少土壤水分蒸发。同时, 在种植后一个月 内均要加强淋水, 确保全苗壮苗。

\section{3 无公害茶树施肥技术的应用}

3. 1 无公害肥料的选择

就绿色无公害的茶叶种植而言, 最为重要的环节即为肥 料篎选。所谓的无公害茶叶, 即为无化学肥料栽培的茶叶, 如常用的硝酸铵化工废料就不能使用。因此, 茶农可从以下 三个方面选择合适的肥料, 以更好地开展种植工作。一是在 农家肥料之中, 沼气肥、农作物秸秆以及堆肥都是高度契合 无公害茶树生长发育的重要肥料; 二是人或动物的排泄物以 及动植物残体也是高效的有机肥料; 三是具备高含量纤维素 且不具备化学物品的原料, 也可以加以使用。

\section{2 无公害肥料的使用}


在进行无公害肥料的配制过程之中, 农户需要切实遵循 包括配料搭配、均衡使用的两大原则。肥料之中, 不同的化 学元素占比、微量元素占比, 直接决定了肥料的效力, 即种植 的情况。例如, 在氮含量的比例上, 茶树的年龄越大, 对氮的 需求也越高, 自然肥料中的氮应当不断增长。根据不同深度 的施肥工作, 对茶树的影响也不尽相同。例如, 深耕肥料能够 促进树苗更好地生长。

\section{4 无公害茶叶的病虫害防治技术}

4. 1 农业防治技术

无论是在原有茶园基础上进行改造, 还是建设全新的茶 园, 茶农的首要任务都是选择合适的茶树种。为了从根本上 避免病虫害的侵袭问题, 茶农必须要结合实际情况, 选择具 备强抗病虫害能力的树种进行种植。同时, 为了避免大型病 虫害问题的侵袭, 通常情况下树种不高于 80 厘米, 因此茶农 必须定期展开对茶树的修剪工作。尤其是秋季、冬季较为寒 冷的季节, 需要对土壤表层展开施肥和翻耕, 对土壤表层的 病虫、虫卵等进行修剪, 确保茶树更好地吸收养分, 全面抑制 病虫害的滋生和繁衍。

\section{2 物理防治技术}

在无公害茶叶的种植过程之中, 物理方法常被运用于部 分人工相对较易捕杀的病虫害问题, 例如, 茶丽纹象甲和茶毛 虫等。常用的方法有采取灯光的方式将害虫杀死, 或采用色板 诱捕害虫等。除了病虫以外, 杂草也会影响茶树的正常生长发 育, 茶农也要做好相应的田间管理工作, 及时清除杂草。

\section{3生物防治技术}

根据现有的技术情况来看, 生物防治技术是目前最为有 效且契合无公害需求的一种病虫害防治手段, 例如, 寄生蜂、 慓虫都是茶树常见病虫的天敌。所以在具体种植的过程之中, 农户可以有意识地引入上述病虫害的天敌, 从生物角度完成 防治工作, 最大程度上避免对茶树产生负面作用。

\section{4 化学防治技术}

为了更好地避免农药对茶树的负面作用, 农户应当选择 残留较低、毒性较低, 无其是对人体影响最小的农药来进行 防治工作。通常情况下, 农药的喷酒往往是采用喷雾式的方 法, 对茶树和土壤不同的部位, 要有针对性地完成喷酒, 从而 达到更好的防治效果。

\section{5 人工管理}

首先, 自然环境是不可改变的, 但是人为可以改善环境。 有的茶园身处贫瘦土地, 我们可以加大改造力度, 走可持续 发展道路, 在周围多种植树木, 开沟排水, 修建防护林, 从而
改善土地环境。其次, 我国现在对技术型人才的培养很重视。 队伍无公害茶叶来说, 不仅需要经验丰富的实践人员, 更需 要专业知识储备强的技术人员, 定期对茶叶进行抽样检查, 预防病虫害和其他问题的爆发。在无机物农药和生物农药的 运用中, 赋予指导性意见。以及在平时的种植中, 发挥主导作 用。然后, 我们在不断改革, 变化, 实践中取得的宝贵经验都 应该有相关人员的记录。不管是大型病虫害的预防还是罕见 的危机, 都是值得以后借鉴和学习的。成功案例的关键, 施肥 时间, 病虫害的及时预防, 针对天气变化的对应措施, 都是不 可忽视的问题。人工的完善和记录, 可以使我们在无公害茶 叶的种植和管理技术上更进一步。最后, 除了种植过程中的 无公害, 在茶叶采摘, 包装, 运输上的安全问题也是需要得到 保障的。工厂应选在远离重工厂, 无污染的地区, 相关操作人 员应配备相应措施, 保证其干净卫生。包装茶叶的材料也应 该经过国家质量安全检验标准。与此相关的操作人员都是应 该经过专业培训, 严格要求的。这样才能保证无公害茶叶的 高标准, 低残留, 真正的无公害。

\section{6 建立生产档案}

为了保证茶叶的质量, 茶园内的所有生产活动都应该详 细地记录在档案中, 包括土壤管理、施肥、灌溉、修剪枝叶 等。其中, 化肥和农药的使用情况需要着重记录, 种类、时间、 方法、用量等缺一不可。由此可以建立起化肥农药可追溯系 统, 对于后期加工和销售具有重要意义。

\section{7 结语}

我国是茶叶生产大国和消费大国, 但多年来茶叶产量不 高且茶叶上残留有害物质, 大大影响了我国茶叶产业的发 展。所以, 现在绿色无公害茶叶越来越受人们的欢迎。生产 绿色无公害茶叶, 不仅能够让人们放心品尝优质的茶叶, 而 且能提高茶农户的收益。因此, 应不断优化绿色无公害茶叶 栽培技术, 提高绿色无公害茶叶的产量和品质, 满足市场需 求, 并促进茶农增收。

\section{[参考文献]}

[1]李学贵.绿色无公害茶叶种植与管理技术[J]. 吉林农 业,2019(06):81.

[2]祝迎涁.绿色无公害茶叶种植与管理技术[J].江西农 业,2019(04):9.

[3]陈瑶.绿色无公害茶叶种植与管理技术浅析[J].农业 与技术,2018(23):109-110.

[4] 孔繁星.绿色无公害茶叶高效种植与管理技术分析 [J].南方农业,2018(35):13-14. 